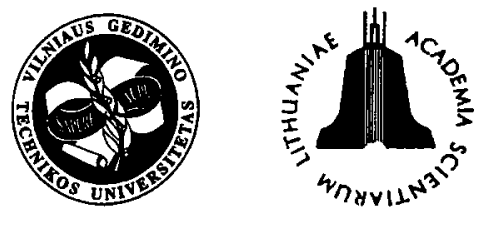

JOURNAL OF CIVIL ENGINEERING AND MANAGEMENT

http:/www.vtu.It/english/edition

2002, Vol VIII, No I, 34-4I

\title{
THE INVESTIGATION OF LOAD CARRYING CAPACITY OF ELASTIC-PLASTIC STRAIN HARDENING BISTEEL I-SECTION BEAMS
}

\author{
Arūnas Jaras', Rimantas Kačianauskas ${ }^{2}$ \\ ${ }^{1}$ Numerical Modelling Laboratory, E-mail: arunas.jaras@st.vtu.lt ${ }^{2}$ Dept of Strength of Materials, \\ Vilnius Gediminas Technical University, E-mail: mopror@adm.vtu.lt \\ Sauletekio al. 11, LT-2040 Vilnius, Lithuania
}

Received 3 Jan 2002; accepted 1 Febr 2002

\begin{abstract}
In the present study, CPT is modelled by static elastic-plastic small strain finite element method (FEM) analysis of axi-symmetric problem. Undrained soil properties and Tresca yield criterion is used for determining cone resistance of clay. Sand is modelled by using drained soil properties and Mohr-Coulomb yield criterion. Cone penetration problem is formulated as a collapse load problem. Associated and non-associated flow rules were used for modelling.

A number of numerical experiments were performed to determine rational size of discrete region. Received dimensions of region were used for further research.

Cone factor $N_{c}$ for clay was obtained and the comparison of $N_{c}$ values with other theoretical solutions is presented. A conclusion may be made that the limit of the validity of geometrically linear systems has been reached. The evaluation of the effect of cone penetration requires the analysis of large strains to be made.
\end{abstract}

Keywords: bisteel I-section beam, plastic analysis, hardening, steel strength, load carrying capacity, capacity moment.

\section{Introduction}

The design of tall structures for buildings and bridges has resulted in many challenges to structural engineers. Development of steel materials and structures has made significant strides to the forefront of the constructional area. A review of recent developments in steel sections and structural systems may be found in [1-2]. The development of higher-strength steels allowed to reduce sectional dimensions, as well as weight and cost of the entire structure, therefore composite structures with higher-strength steel have been extensively used. However, reduction of dimensions is limited by buckling, structural and technological requirements.

The main research and practical development during the last decade was mainly focused on the composition of higher-strength steel and concrete [3-4]. Other possibilities to produce more efficient structures without losses of their load carrying capacity include compositions of different steels. Perhaps, the simplest idea of bisteel composition is based on built-up members to increase the load carrying capacity of structures under loading. The built-up technique consists in strengthening flanges, and details of different covering technologies may be found in [5-9].

Similar technology has been also used for develop- ment of bisteel members and may be implemented in different ways: arrangement of higher-strength steel section in the regions of maximum moments [10], construction of hybrid beams fabricated by using a higher-strength steel for flanges, then in the web [8-11] and composition of higher-strength steel inclusions for flanges in the region of maximum stresses [8-9, 11-14].

The present paper is focused on higher-strength steel inclusions in the flanges of simple I-section beams. The aim of the paper is to develop and verify the explicit analytical model suitable for describing and investigating the load carrying capacity of simply supported Isection bisteel beams subjected to uniformly distributed quasistatic load in respect of plastic deformation. A particular case of perfect plasticity has been already presented in [14], while this paper is mainly focused on general case, including strain hardening. The load carrying capacity condition is expressed here in terms of bending moment. The variation of plastic penetration and different mechanical properties of higher-strength steels is taken into account.

The proposed analytical model has been also tested numerically by the finite element method. The ANSYS code and tetrahedral elements have been used for this purpose. The results of numerical experiments are used to verify the proposed analytical model. 


\section{Geometry and materials}

The bisteel beam presents a composition of higherstrength steel inclusions for the flanges in the region of maximum stresses and of lower-strength steel for remaining volume of the beam (Fig 1). The term "higher strength steel" is meant to describe structural steel of over $260 \mathrm{MPa}$ nominal yield strength in tension.

The beam geometry described in Cartesian coordinates $0 x y z$ with longitudinal coordinate $z$ and is defined by span length $l$ (Fig 1). Due to technological reasons the cross-section remains constant and is defined by crosssection height $h$. Geometry of flanges is defined by $b_{f}$ and $t_{f}$ while the geometry of web is defined by dimensions $h_{w}$ and $t_{w}$. In order to avoid local instabilities or construction of the stiffeners, the dimensions of crosssection are fixed according to well-known proportions, for example, those of standard sections.

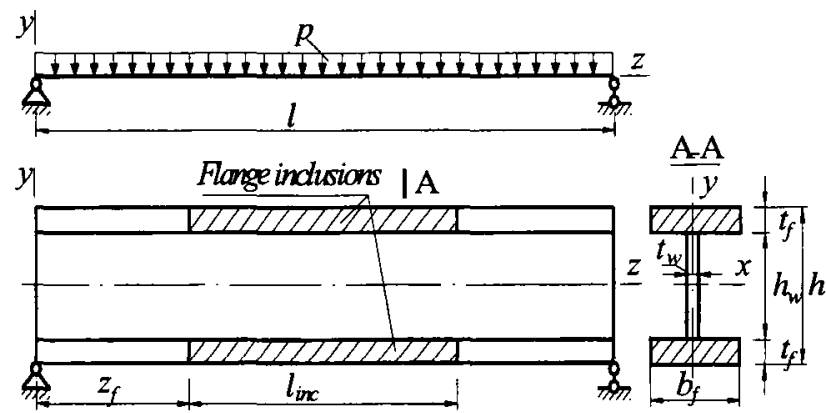

IA

Fig 1. I-section bisteel beam

Since the bending moment diagram for simply supported beam by uniformly distributed load $p$ is usual a parabola with the maximal value at the centre, the higherstrength inclusions are constructed in the central part of the beam. The length of flange inclusions is denoted by $\operatorname{lin}_{c}$.

Material behaviour of both higher-strength flange inclusions and lower-strength steel of remaining volume of beam is described by bilinear diagrams (Fig 2).

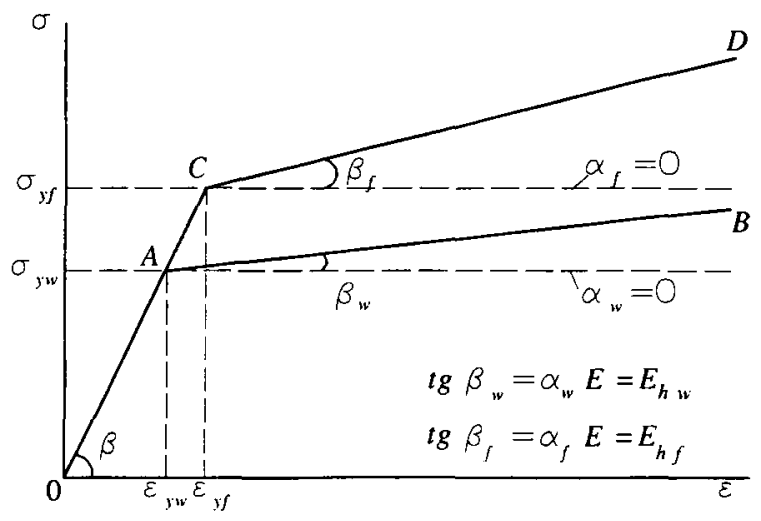

Fig 2. Stress-strain diagram
Elastic branches $O A$ or $O C\left(\sigma<\sigma_{y}\right)$ are described by linear elastic relation:

$$
\sigma=E \varepsilon,
$$

where $E$ is elasticity modulus, while plastic branches $A B$ and $C D\left(\sigma \geq \sigma_{y}\right)$ are defined by relation [15]:

$$
\sigma=\sigma_{y}+\alpha E\left(\varepsilon-\varepsilon_{y}\right)
$$

where $\alpha$ is hardening ratio defined as the ratio of hardening and elasticity modulus $\left(\alpha=E_{h} / E\right)$. Elasticity modulus $E$ is the same for both materials. Perfectly plastic material is considered here as particular case with $\alpha=0$. The hardening influence is investigated in [16, 17]. While yield stress $\sigma_{y}$ and hardening ratio $\alpha$ are different, they are denoted for inclusions as $\sigma_{\mathrm{yf}}$ and $\alpha_{f}$, and as $\sigma_{\mathrm{yw}}$ and $\alpha_{w}$ for remaining volume of the beam respectively. Investigation of variation of the yielding stress ratio (inhomogeneity ratio) $s=\sigma_{y f} / \sigma_{y \mathrm{w}} \geq 1$ as main modelling variables is one of the most importand issues considered in this paper. According to the valid structural steel standard, the inhomogeneity ratio may vary in the range of $1 \leq s \leq 1.8$.

\section{Yielding model}

Elastic plastic analysis of structural members is predefined by traditional assumptions used in mechanics of solids and structures and by yielding model according to which yielding may take place at a cross-section. The yielding manner affects final load carrying capacity and stiffness of structural member. In the framework of the current investigation, geometrically linear two-dimensional bending beam is considered as slender beam based on Bernoulli hypothesis about straight and undeformed section. Consequently, deformations caused by shear stresses are neglected, therefore one-dimensional stressstrain state defined by normal stress $\sigma$ and strain $E$ remains and relations (1-2) are valid. This approach does not require any discussion about hardening model because work hardening is simply transformed to strain hardening. Influence of local contact stresses between both materials is also neglected.

Generally, yielding model is called to fact that yielding starts when the yield limit $\sigma_{y}$ reaches in the most stressed fibre and extends proportionally to increasing loading. Assuming that tensile stress-strain curve (Fig 2) is identical with that in compression, distribution of stresses and strains in the lower half of the beam is the same as in the upper one and neutral axis remains at centroid axes. This results in symmetric linear distribution of strains at any section.

For homogeneous beam the yielding may be predefined in a unique way for a given load. Thus yielding starts in the outer fibres and causes bilinear stress distribution. This is not the case for bisteel beam, where yielding may take place both in higher-strength flanges as well as in lower-strength web independently, providing multilinear stress distribution at section. This distribu- 


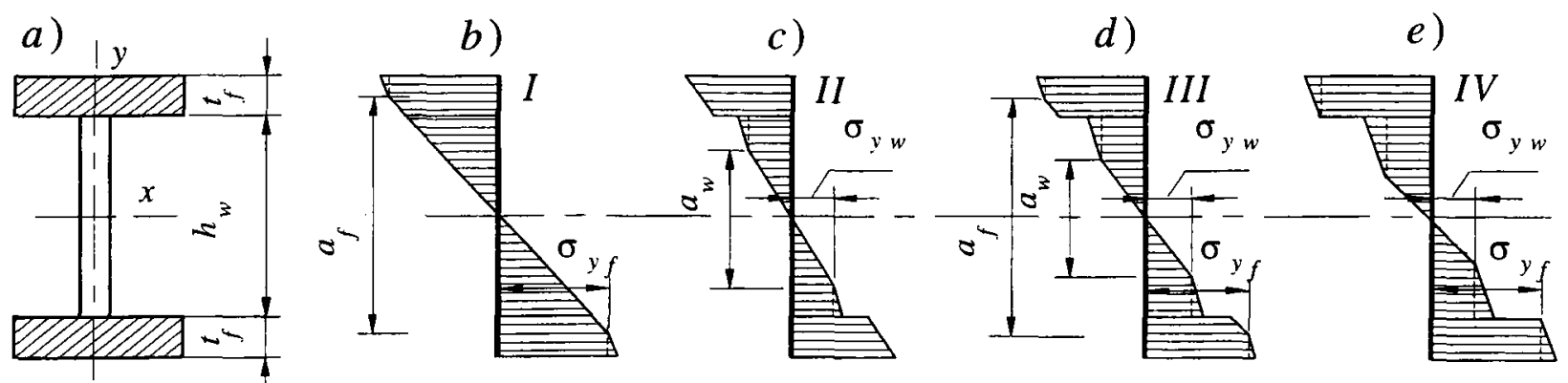

Fig 3. Penetration of plastic strain in the bisteel I-section: b) plastic strain in web; c) plastic strain in flanges; d) limited plastic strain both in flanges and web; e) full plasticity of flanges

tion caused different yield limits for both steels. A case study of the above-mentioned distribution is presented in Fig 3, where notations I-IV indicate different yielding models. Initiation of yielding depends on yielding stress ratio $s$ and geometry of I-section. For the $s<h / h_{w}$, yielding starts in outer fibres of the section, while spreading of plastic region corresponds to those observed in homogeneous section (Fig 3b). Here elastic core is defined by high $a_{f}$ and remains inside the flanges. For the value $s>h / h_{w}$, yielding starts at the outer fibres of the web (Fig 3c), where elastic core $a_{w}$ remains inside the web. In the most general case, any load increase provides yielding of both the flanges and the web (Fig 3d) with two elastic cores $a_{f}, a_{w}$. By increasing load, full yielding may be achieved at flanges (Fig 3e). This yielding model has to be considered as a particular case of general model (III). The increase of loading is limited by prescribed value of elastic core $a_{\lim }$, where $a \geq a_{\lim }$. In general case (III), stress diagrams present four different regions. Stresses in the elastic region of the web $\left(|y| \leq a_{w}\right)$ are defined as $\sigma_{e l w}(y)$ and for flanges $\left(h_{w} \leq|y| \leq a_{f}\right)$ they are defined as $\sigma_{e l f}(y)$. In plastic regions for web $\left(a_{w} \leq|y| \leq h_{w}\right)$ stresses are defined by distribution $\sigma_{p \mid w}(y)$, while for flanges $\left(a_{f} \leq|y| \leq h\right)$ they are defined as $\sigma_{p l f}(y)$.

Actually plastic stresses are composed of two addends corresponding to perfect plasticity and hardening:

$$
\begin{aligned}
& \sigma_{p l w}(y)=\sigma_{p w}(y)+\sigma_{h w}(y), \\
& \sigma_{p l f}(y)=\sigma_{p f}(y)+\sigma_{h f}(y) .
\end{aligned}
$$

Explicit expression of the above-mentioned stresses are defined by the following formulae:

$$
\begin{gathered}
\sigma_{e l \mathrm{w}}=\sigma_{y \mathrm{w}} \frac{2 y}{a_{w}}, \quad \sigma_{e l \mathrm{f}}=\sigma_{y \mathrm{f}} \frac{2 y}{a_{f}}, \\
\sigma_{p w}=\sigma_{y w}, \sigma_{p \mathrm{f}}=\sigma_{y \mathrm{f}}, \\
\sigma_{h w}=\alpha_{w} \sigma_{y w}\left(\frac{2 y}{a_{w}}-1\right), \quad \sigma_{h f}=\alpha_{f} \sigma_{y f}\left(\frac{2 y}{a_{f}}-1\right) .
\end{gathered}
$$

The above expressions (4) present the basis for load carrying capacity and stiffness analysis of bisteel I-section beams.

\section{Investigation of the load carrying capacity}

Different design procedures and criteria are put forward to evaluate the load carrying capacity of structural members, in general, and of plane bending beams, in particular $[8,11,18]$. The elastic plastic approach assumes that the beam resists loads from the beginning of yielding and development of structural damage to full plastic collapse. Particularly, plastic limit moment $M_{c}(z)$, which can withstand the action of bending moment $M(z)$ occuring due to external loading, is the most suitable characteristic used to define load carrying capacity of the section. In future, $M_{c}$ is termed here as the capacity moment. Longitudinal coordinate $z$ denotes the section under consideration. Thus resistance of beam in pure bending or load carrying capacity is defined by yielding condition in terms of moments:

$$
M(z) \leq M_{c}(z) .
$$

Evaluation of capacity moment $M_{c}(z)$ is a rather sophisticated task. The most popular way of doing this (recommended in design codes $[11,18]$ ) is to derive a relationship between $M_{c}$ and depth of plastic penetration $c$ or elastic core $a$. Thus we assume the plastic moment $M_{c}(z)=M_{c}(a(z))$. For the case, where the beam is subjected to the uniformly distributed load $p$, the bending moment is parabola with the equation [19]:

$$
M(z)=\frac{p}{2}\left(1 z-z^{2}\right) .
$$

The moment equilibrium between stresses $\sigma$ and bending moment $M$ provides expression for capacity moment:

$$
M_{c}(z)=\int_{A} \sigma_{y}(z, y) y d A .
$$

For general case III (Fig 3d), the capacity moment $M_{c}(z)=M_{c p h}=M_{c I I I}(z)$ involving hardening may be presented as a sum of three components having different physical meanings:

$$
M_{c \mathrm{ph}}=M_{c e}+M_{c p}+M_{c h} .
$$


Here the subscripts $e, p$ and $h$ denote different physical origin of the components and reflects the influence of elastic, perfectly plastic and hardening stresses. Each of the components $i(i=e, p, h)$ involves capacity moments of stresses in web and flanges:

$$
M_{c i}=M_{i w}+M_{i f} \text {. }
$$

For perfect elastic plasticity, when $\alpha=0$, the moment $M_{c h}$ vanishes and capacity moment $M_{c}(z)=M_{c p p}$ contains a simpler expression:

$$
M_{c p p}=M_{c e}+M_{c p} \text {. }
$$

For pure elastic case, when $a_{w}=h_{w}, a_{\mathrm{f}}=h$, the moments $M_{c p}$ and $M_{c h}$ vanish and capacity moment $M_{c}(z)=M_{c e l}$. Here

$$
M_{c e l}=M_{c e} \text {. }
$$

It proves convenient to divide section height (Fig 3) into four segments, and integration of stresses (III) within the segments provides separate components of capacity moments $(8-11)$ :

$$
\left.\begin{array}{c}
M_{e w}=2 t_{w} \int_{0}^{a_{w} / 2} \sigma_{e l w}(y) y d y, \\
M_{e f}=2 b_{f} \int_{h_{w} / 2}^{a_{f} / 2} \sigma_{e l f}(y) y d y,
\end{array}\right\}
$$

Since we deal with capacity moments only, subscript $c$ is omitted. In particular cases (for yielding models I, II, IV) some of the above moments turn to zero.

Assuming the geometry of section defined by dimensional height $h$, the other dimensions may be defined by non-dimensional values [20].

$$
\left.\begin{array}{l}
h_{w}=\bar{h}_{w} h, \quad t_{w}=\bar{t}_{w} h, \quad b_{f}=\bar{b}_{f} h, t_{f}=\bar{t}_{f} h, \\
a_{w}=\bar{a}_{w} h, \quad a_{f}=\bar{a}_{f} h, \quad \mathrm{z}=\overline{\mathrm{z}} 1 .
\end{array}\right\}
$$

The moments (6) and (7) may be also expressed in terms of non-dimensional variables. The external bending moment is presented as:

$$
M(\bar{z})=\bar{M}(\bar{z}) p l^{2},
$$

where non-dimensional function

$$
\bar{M}(\bar{z})=\frac{1}{2}\left(\bar{z}-\bar{z}^{2}\right) .
$$

Expressing yielding stress $\sigma_{y}(z, y)$ by a single dimension parameter $\sigma_{y},\left(\sigma_{y} \equiv \sigma_{y \mathrm{w}}\right)$ the non-dimensional capacity moment (7) may be presented in the same manner:

$$
M_{c}(\bar{z})=\bar{M}_{c}(\bar{a}(\bar{z})) \sigma_{y} h^{3},
$$

where non-dimensional quantity $\bar{M}_{c}$ is a function of the elastic core $(\bar{a}(\bar{z}))$.

After integration of (12) and in respect of (4) and (13), individual components of capacity moments (8-9) may be presented explicitly:

$$
\left.\begin{array}{l}
\bar{M}_{e w}(\bar{z})=\bar{t}_{w} \frac{\bar{a}_{w}^{2}(\bar{z})}{6}, \\
\bar{M}_{e f}(\bar{z})=s \bar{b}_{f}\left(\frac{\bar{a}_{f}^{2}(\bar{z})}{6}-\frac{\bar{h}_{w^{3}}{ }^{3}}{6 \bar{a}_{f}(\bar{z})}\right)
\end{array}\right\}
$$

$$
\left.\begin{array}{l}
\bar{M}_{p w}(\bar{z})=\bar{t}_{w}\left(\frac{\bar{h}_{w}{ }^{2}}{4}-\frac{\bar{a}_{w}{ }^{2}(\bar{z})}{4}\right), \\
\bar{M}_{p f}(\bar{z})=s \bar{b}_{f}\left(\left(\frac{\bar{h}_{w}}{2}+\bar{t}_{f}\right)^{2}-\frac{\bar{a}_{f}^{2}(\bar{z})}{4}\right),
\end{array}\right\}
$$

$$
\left.\begin{array}{c}
\bar{M}_{h w}(\bar{z})=\bar{t}_{w} \alpha_{w}\left(\frac{\bar{h}_{w}^{3}}{6 \bar{a}_{w}(\bar{z})}-\frac{\bar{h}_{w}^{2}}{4}+\frac{\bar{a}_{w}^{2}(\bar{z})}{12}\right) \\
\bar{M}_{h f}(\bar{z})=s \bar{b}_{f} \alpha_{f}\left(\frac{4}{3 \bar{a}_{f}(\bar{z})}\left(\frac{\bar{h}_{w}}{2}+\bar{t}_{f}\right)^{3}-\right. \\
\left.\left(\frac{\bar{h}_{w}}{2}+\bar{t}_{f}\right)^{2}+\frac{\bar{a}_{f}^{2}(\bar{z})}{12}\right)
\end{array}\right\}
$$

Expressions (17) predicting capacity of individual sections have to be applied for evaluating load carrying capacity of the entire beam.

The variation of capacity moment in the middle of the beams $M_{c 0}$ due to different values of plastic penetration $c_{0}$ for section with non-dimensional $\bar{h}_{w}=0.87833, \bar{t}_{w}=0.04, \bar{b}_{f}=0.53333, \bar{t}_{f}=0.060833$ is illustrated in Fig 4. The influence of higher-strength steel inclusions is expressed in terms of different yielding stress ratio (inhomogeneity ratio) $s$ with values $s=1.0,1.2,1.46,1.74$. Each of the inhomogeneity ratio is illustrated for perfect plasticity $\alpha=0$ and hardening with $\alpha=0.1$.

Here for the sake of convenience the elastic core is reverted to the depth of plastic penetration: $\bar{c}_{0}=\frac{h-a_{w}}{h}$

It follows from the longitudinal distribution of bending moment (6) that the load carrying capacity problem (5) may by reduced to capacity of midspan with $z=l / 2$ : 


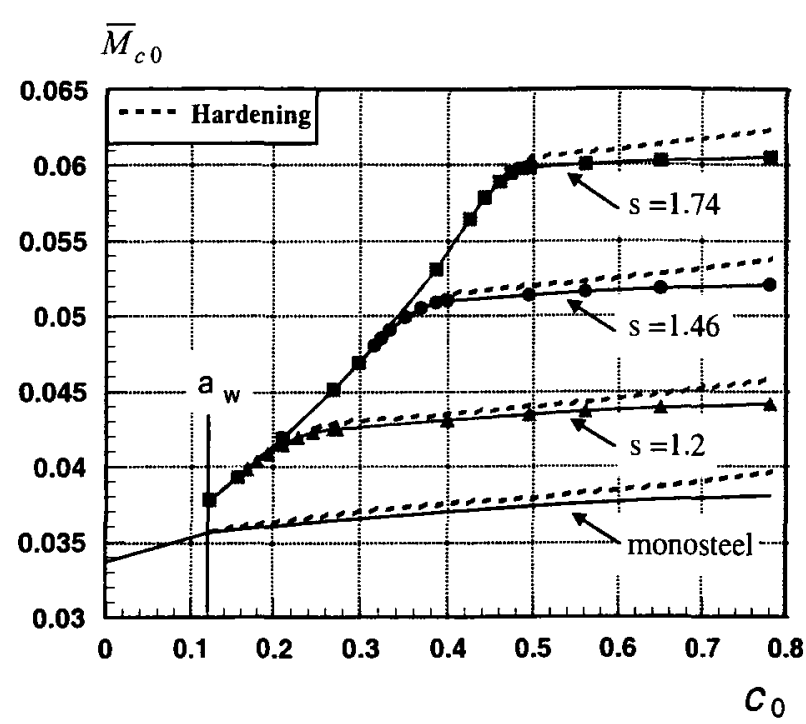

Fig 4. Diagram $\bar{M}_{c 0}=f\left(\bar{c}_{0}\right)$

$$
M_{\max } \leq M_{c 0},
$$

where subscript 0 will be referred in the future to midspan, while the capacity moment $M_{c 0}$ is controlled by the limit height of elastic core $a_{0}$. Since the value of maximal bending moment $M_{\max }=M_{0}(\bar{z}=l / 2)$ may be obtained according to (15) and equals $1 / 8$, condition (18) may be also presented in non-dimensional form as:

$$
\bar{M}_{c 0}\left(\bar{a}_{0}\right) \geq 1 / 8 \text {. }
$$

By taking into account (14) and (16), this condition may be reversed for evaluating the limit load

$$
p \leq \frac{8 \sigma_{y} h^{3}}{1^{2}} \bar{M}_{c 0}\left(\bar{a}_{0}\right)
$$

Expressions (19) and (20) provide load carrying capacity problem of beam explicitly and may be applied for design as well as for evaluating the limit load.

\section{Computation of plastic zones}

Evaluation of distribution of capacity moment $M_{c}(z)$ requires computation dimensions of plastic zones. In the limit case of condition (5) for the distributed loading, the capacity moment is shaped by the external bending moment (6). Actually, expressions (8-11) depend on the depth of elastic core $a=a(z)$, which is function of section position $z$. Plastic deformations extend over the region where the bending moment $M(z)$ exceeds the maximum elastic capacity moment $M_{c e l}(z)$. According to the above statement, the longitudinal distribution of plastic zones presents a picture illustrated in Fig 5. It reflects different yielding models presented in Fig 3. After submission of bending moment (14-15) and capacity moment $(8)$ and (17) the non-dimensional height of elastic core $\bar{a}=\bar{a}(\bar{z})$ can be found by solving cubic algebraic equation

$$
A \bar{a}^{3}+B(\bar{z}) \bar{a}+C=0 .
$$

The equation coefficients are expressed as

$$
\begin{aligned}
B(\bar{z}) & =B_{1}(\bar{z})-B_{2}, \\
C & =C_{1}+C_{2} .
\end{aligned}
$$

The expressions of variables and coefficients of cubic equation (21) reflect the above yielding models (Fig 3). As matter of fact two cases are observed.

For the yielding model I (when $a=a_{f}$ ) they are:

$$
B_{1}(z)=-\frac{48 M_{0}}{\sigma_{y \mathrm{f}} \mathrm{b}_{\mathrm{f}} l^{2}}\left(l z-z^{2}\right), \quad C_{1}=-\bar{C}_{1} h_{w}^{3} .
$$

For the remaining yielding models II-IV (when $a=a_{w}$ ) they are:

$$
B_{1}(z)=-\frac{48 M_{0}}{\sigma_{y w} \mathrm{t}_{\mathrm{w}} l^{2}}\left(l z-z^{2}\right), \quad C_{1}=\bar{C}_{1} h_{w}^{3},
$$

where $\bar{C}_{1}=\frac{2 \mathrm{t}_{\mathrm{w}}}{b_{f}}$.

The expressions of coefficients $A, B_{2}$ and $C_{2}$ for all yielding models I-IV are presented in Table 1.

The solution of equation (21) using computer algebra system is presented in a form

$$
a=\frac{D}{3 A}-\frac{B(\bar{z})}{D},
$$

where

$$
D=\left(\frac{1}{2}\left(-27 A^{2} C+\sqrt{108 A^{3} B(\bar{z})^{3}+729 A^{4} C^{2}}\right)\right)^{1 / 3}
$$

Particularly in the case of perfect plasticity of the fourth yielding model (Fig 3) the algebraic equation 21 takes a quadratic form

$$
a^{2}-B(\bar{z})=0,
$$

the solution of which is presented in a form:

$$
a=\sqrt{B(\bar{z})} \text {. }
$$

The explicit solutions (26) or (28) obtained here may be applied for evaluating plastic zones along the bisteel beam for different yielding models as it is illustrated in Fig 5 .

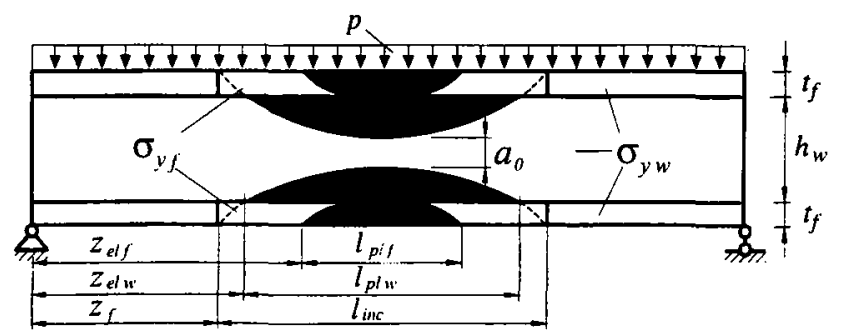

Fig 5. Distribution of plastic zone in a bisteel beam 
Values of coefficients of cubic equations

\begin{tabular}{|c|c|c|c|}
\hline $\begin{array}{c}\begin{array}{c}\text { Yielding } \\
\text { model }\end{array} \\
\end{array}$ & $A$ & $B_{2}$ & $C_{2}$ \\
\hline I & $1-\alpha_{f}$ & $12\left(\frac{\bar{h}_{w}}{2}+\bar{t}_{f}\right)^{2}-\alpha_{\mathrm{f}} 12\left(\frac{\bar{h}_{w}}{2}+\bar{t}_{f}\right)^{2}$ & $2 \bar{h}_{w}^{3}-\alpha_{f} 16\left(\frac{\bar{h}_{w}}{2}+\bar{t}_{f}\right)^{3}$ \\
\hline $\mathbf{I}_{\mathrm{pp}}$ & 1 & $12\left(\frac{\overline{\mathrm{h}}_{\mathrm{w}}}{2}+\bar{t}_{f}\right)^{2}$ & $2 \bar{h}_{w}^{3}$ \\
\hline II & $1-\alpha_{w}$ & $3 \bar{h}_{w}^{2}-\alpha_{w} 3 \bar{h}_{w}^{2}$ & $-\alpha_{w} 2 \bar{h}_{w}^{3}-\frac{16 \bar{b}_{f}}{\bar{t}_{w}}\left(\frac{\bar{h}_{w}}{2}+\bar{t}_{f}\right)^{3}$ \\
\hline $\mathbf{I}_{\mathbf{p p}}$ & 1 & $3 \bar{h}_{w}^{2}$ & $-\frac{16 \bar{b}_{f}}{\bar{t}_{w}}\left(\frac{\bar{h}_{w}}{2}+\bar{t}_{f}\right)^{3}$ \\
\hline III & $1+\frac{\bar{b}_{f} s^{3}}{\bar{t}_{w}}-\alpha_{w}-\alpha_{f} \frac{\bar{b}_{f} s^{3}}{\bar{t}_{w}}$ & $\begin{array}{l}3 \bar{h}_{w}^{2}+\frac{12 s \bar{b}_{\mathrm{f}}}{\bar{t}_{w}}\left(\frac{\bar{h}_{w}}{2}+\bar{t}_{f}\right)^{2}- \\
\alpha_{w} 3 \bar{h}_{w}^{2}-\frac{\alpha_{\mathrm{f}} 12 s \overline{\mathrm{b}}_{\mathrm{f}}}{\bar{t}_{w}}\left(\frac{\bar{h}_{w}}{2}+\bar{t}_{f}\right)^{2}\end{array}$ & $-\alpha_{w} 2 \bar{h}_{w}^{3}-\frac{\alpha_{f} 16 \bar{b}_{f}}{\bar{t}_{w}}\left(\frac{\bar{h}_{w}}{2}+\bar{t}_{f}\right)$ \\
\hline $\mathbf{I I I}_{\mathrm{pp}}$ & $1+\frac{\bar{b}_{f} s^{3}}{\vec{t}_{w}}$ & $3 \bar{h}_{w}^{2}+\frac{12 s \bar{b}_{f}}{\bar{t}_{w}}\left(\frac{\bar{h}_{w}}{2}+\bar{t}_{f}\right)^{2}$ & 0 \\
\hline $\mathbf{r v}$ & $1-\alpha_{w}$ & $\begin{array}{l}3 \bar{h}_{w}^{2}+\frac{12 s \bar{b}_{f}}{\bar{t}_{w}}\left(\bar{h}_{w} \bar{t}_{f}+\bar{t}_{f}^{2}\right)- \\
\alpha_{w} 3 \bar{h}_{w}^{2}+\frac{\alpha_{f} 12 s \bar{b}_{f}}{\bar{t}_{w}}\left(\frac{4 \bar{t}_{f}^{3}}{3 \bar{h}_{w}}+\bar{t}_{f}^{2}\right)\end{array}$ & $-\alpha_{w} 2 \bar{h}_{w}^{3}$ \\
\hline$\underset{\text { Plastic }}{\mathbf{I V}}$ & 0 & $3 \bar{h}_{w}^{2}+\frac{12 s \bar{b}_{f}}{\bar{t}_{w}}\left(\bar{h}_{w} \bar{t}_{f}+\bar{t}_{f}^{2}\right)$ & 0 \\
\hline
\end{tabular}

Howewer, the coordinates of plastic regions $z_{e l w}$, $z_{e l f}$ as well as flange inclusions $z_{f}$, may be found $\mathrm{di}-$ rectly by solving the equation

$$
M(z)=M_{c \text { el }} .
$$

In the case $M_{c e l} \equiv M_{e l w}^{*}$ solution of the above equation presents a boundary coordinate of plastic region in the web:

$$
z_{e l \mathrm{w}}=\frac{l}{2}-\frac{1}{2 p} \sqrt{(p l)^{2}-8 p M_{e l \mathrm{w}}^{*}} .
$$

When $M_{c e l} \equiv M_{e l f}^{*}$, the solution of equation (29) presents a boundary coordinate of plastic region in the flanges:

$$
z_{e l \mathrm{f}}=\frac{l}{2}-\frac{1}{2 p} \sqrt{(p l)^{2}-8 p M_{e l \mathrm{f}}^{*}} .
$$

Here the moments $M_{e l w}^{*}$ and $M_{e l f}^{*}$ are the bending moments, caused maximum elastic stresses in the outer fibres of the web and flanges respectively.

Since the length of flange inclusions is defined by the boundary of plastic zones, the above expressions (3031) may be used for designing flange inclusions. Therefore the boundary coordinate of inclusions $z_{f}$ may be found in the same manner, by solving the equation 29 :

$$
z_{f}=\frac{l}{2}-\frac{1}{2 p} \sqrt{(p l)^{2}-8 p M_{c e l}} .
$$

Here $M_{c e l}$ is computed for the case of $\sigma_{y} \equiv \sigma_{y w}$.

Finally, the length of plastic regions and the length of flange inclusions may be obtained in a simple manner:

$$
\begin{aligned}
& l_{p l \mathrm{w}}=\frac{1}{p} \sqrt{(p l)^{2}-8 p M_{e l \mathrm{w}}^{*}}, \\
& l_{p l \mathrm{f}}=\frac{1}{p} \sqrt{(p l)^{2}-8 p M_{e l \mathrm{f}}^{*}} \\
& l_{i n c}=\frac{1}{p} \sqrt{(p l)^{2}-8 p M_{c e l}} .
\end{aligned}
$$




\section{Variation of the load carrying capacity}

Using the proposed analytical model the variation of the load carrying capacity is investigated and presented graphically. Here, the yielding condition (5) expressed by moments $M(z)$ and $M_{c}(z)$ has been examined numerically. The distribution of capacity moments $M_{c}(z)$ defined in (7) has been obtained according to $(8-12)$ and (17), where boundaries of plastic zones are shaped according to general solutions (26) and (28).

The bisteel I-section beam with length $l \quad(l=1.0)$, height $h(h=0.12 l)$ and remaining dimensions $h_{w}=0.87833 h, \quad t_{w}=0.04 h, \quad b_{f}=0.5333 h$, $t_{f}=0.060833 h$ is considered as an illustrative example.

Appropriate influence of higher-strength steel inclusions to load carrying capacity may be already observed in the elastic stage of the beam. The maximal elastic capacity moments $M_{c e l}$ with the non-dimensional values $\bar{M}_{c e l 1}=0.0332$ for monosteel $(s=1.0)$ and $\bar{M}_{c, e / 2}=0.0378$ for bisteel beams $(s=1.2)$ respectively, are presented in Fig 6 . Here the $l_{\text {incl } 1}, l_{\text {inc } 2}$ are the length of inclusions obtained, according to inhomogeneity ratios $s=1.1385$ and $s>1.1385$ respectively.

As it follows from the illustration, increasing $s>1.1385$ produces a higher length of inclusions, but it does not increase the beam capacity in the elastic range.

However, the influence of higher-strength steel inclusions expressed in terms of capacity moment $M_{c}$ is more significant if the plastic deformation is permitted. Here the depth of plastic core $a$ as well as the value of inhomogenity ratio $s$ is a very important issue. The capacity moments variation due to different values of inhomogeneity ratio $s$ with limit value of elastic core

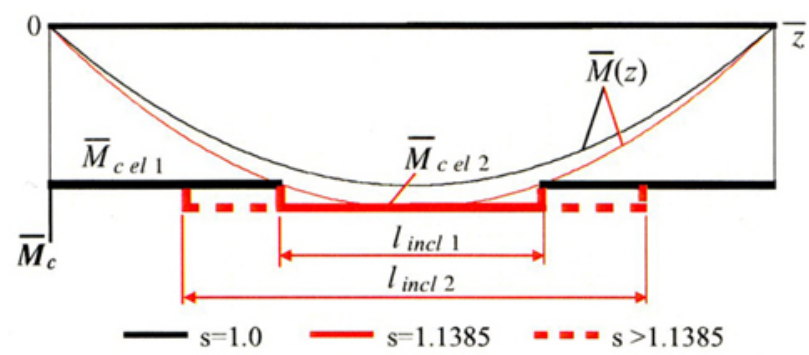

Fig 6. Distribution of elastic capacity moments

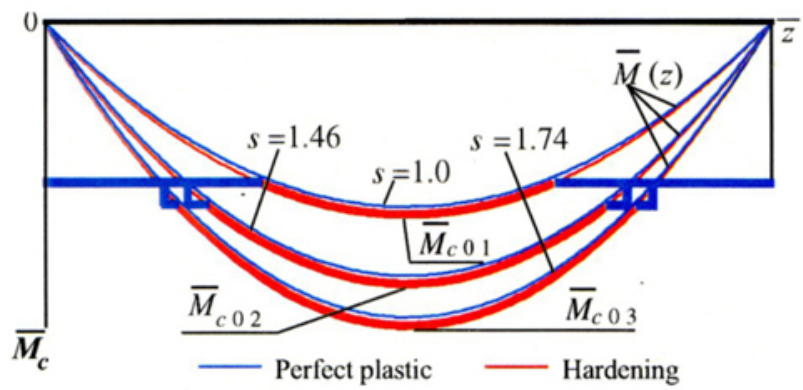

Fig 7. Distribution of capacity moments $a_{0}=0.25 h_{w}$ for the above-mentioned beam is illustrated in Fig 7.

Maximum values of non-dimensional $\bar{M}_{c 0}$ at the midspan $\quad \bar{M}_{c 01}=0.0395, \quad \bar{M}_{c 02}=0.0536 \quad$ and $\bar{M}_{c 03}=0.0623$ illustrate possible increasing of the load carrying capacity of the beam up to $50 \%$ in respect of growing of inhomogeneity, which may be reverted by (20) to limit load. The capacity moment variation with the biggest value of $a_{0} \geq 0.25 h_{w}$ has the same character.

\section{FEM investigation}

The beam with the above geometry has been solved numerically. Higher-strength steel flange inclusions with yielding limit $\sigma_{y f}=300 \mathrm{MPa}$, which produces inhomogeneity ratio $s=1.2$ has been taken for illustration. Assuming the elastic core in the midspan of the beam with $a_{0}=0.575 h_{w}$, the limit load obtained according to (20) produces the value $p=151.7 \mathrm{KN} / \mathrm{m}$. The length of higher-strength steel inclusions obtained by (35) yields the value $l_{\text {incl }}=0.49421$.

The aim of numerical experiments is to verify the analytical model by checking the distribution of plastic zones $(26,28)$.

The ANSYS code [21] and tetrahedral elements SOLID-92 [22] have been used for this purpose. The FEM mesh of bisteel beam is presented in Fig 8 .

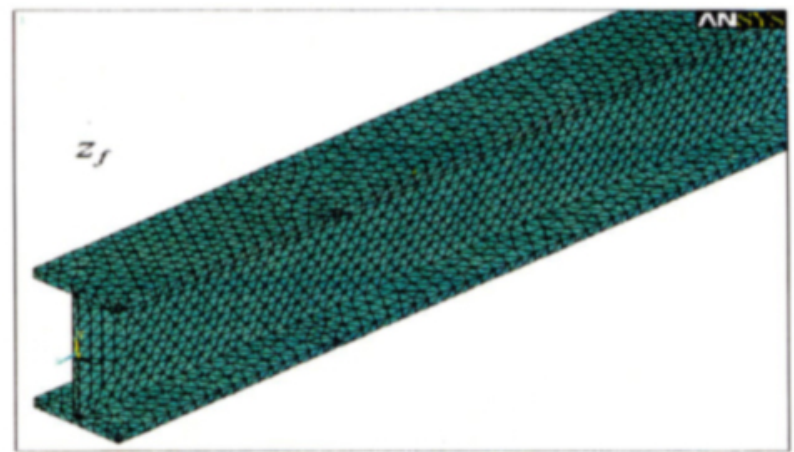

Fig 8. FEM mesh

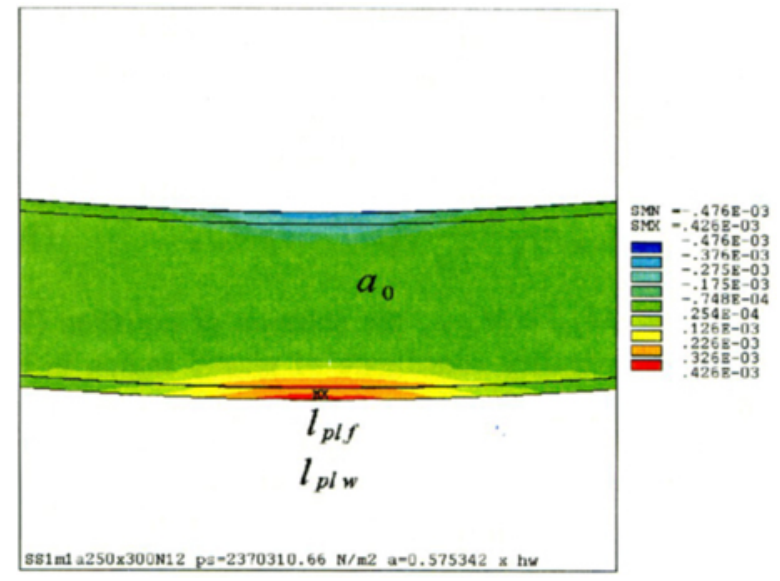

Fig 9. Distribution of plastic deformation in the bisteel beam 
The distribution of strains (Fig 9) illustrates spreading of plastic zones where the elastic zones are covered by green area. The numerically obtained values of elastic core $a_{0}=0.57 h_{w}$ and the length of plastic zones in the flanges $l_{p l f}=0.288 l$ and web $l_{p l w}=0.39 l$ present a good agreement with analytical solution $a_{0}=0.575 h_{w}, l_{p l f}=0.305 l, l_{p l w}=0.373 l$. Experiments with different values of input date show validity of analytical solution $(30,31)$ if the length of the higher-strength inclusions does not exceed $l_{\text {incl }} \leq 0.6 l$.

As provided in [14] for longer flange inclusions, the character of plastic deformation is changed. The further research is, however, necessary to consider the behaviour of bisteel beams outside the range of $60 \%$ limit of relative length of higher-strength steel inclusions.

\section{Remarks and conclusions}

The analytical model for estimating load carrying capacity of bisteel beams has been developed. It involves explicit expression for capacity moment $M_{c}$ or limit value of distributed load $p$ as a function of admissible plastic penetration $c$ and inhomogeneity of the beam inclusions. The investigation of the model of bisteel beam with flange inclusions allows to shape the following conclusions:

1. Numerical analysis shows the validity of analytical model for short flange inclusions, still $l_{i n c l} \leq 0.6 l$.

2. When the inhomogeneity ratio $s=1.46$ the case of limited plastic penetration allowed to increase the load carrying capacity up to 1.35 once in respect of monosteel beam.

3. The influence of material hardening increases the load carrying capacity insignificantly, maximally up to $3 \%$.

4. The proposed analytical model may be used for further research by solving the problems of analysis and optimization of bisteel I-section beams in respect of the strength conditions.

Further research is, however, necessary to consider the behaviour of these beams outside the range of $60 \%$ of relative length of higher-strength steel inclusions.

\section{References}

1. Dowling P. J., Burgan B. A. Steel Structures in the New Millennium. Journal of Constructional Steel Research, 1998, Vol 46 (1-3), Paper No 423.

2. Kvedaras A. K., Kudzys A., Vaitkevičius V. Efficient Future Strategies for Constructing with Steel in Lithuania. Journal of Constructional Steel Research, 1998, Vol 46 (1-3), Paper No 19.

3. Kalamkarov A. L., Kalpakov A. G. Analysis, design and optimisation of composite structures. Willey, 1997. $365 \mathrm{p}$.

4. Uy B. Axial compressive strength of short steel and composite columns fabricated with high strength steel plate Steel and Composite Structures, 2001, Vol 1, No 2, p. 171185.
5. Fanella D. A., Amon R., Knobloch B., Mazumder A. Steel design for Engineers and Architects. New-York, Van Nostrand Reinhold, 1992. 503 p.

6. Owens G. W., Knowles P. R. Steel Designers' Manual. 5th ed. Oxford, Blackwell Scientific Publlications, 1994, p. 1266.

7. Krajnc A., Beg D. Optimal design of steel frames made of welded buit-up members. Journal of Constructional Steel Research, 1998, Vol 46 (1-3), Paper No 011.

8. Belenia E. I., et al. Metalličeskije konstrukciji. Moskva: Strojizdat, 1986. 560 p. (in Russian).

9. Belenia E. I., et al. Metalličeskije konstrukciji. Spec kurs. Moskva: Strojizdat, 1982. 472 p. (in Russian).

10. Bresler B., Lin T. Y., Scalzi J. B. Design of steel structures. 2 nd ed., New York, John Willey \& Sons, 1968, p. 830 .

11. Posobije po projektirovaniju stalnych konstrukcij (k SniP II-23-81*). Moskva: CTIP Gosstroja SSSR, 1989. 148 p. (in Russian).

12. Černov N. L., Šerbakin V. S., Tarasenko V. L. Pročnost izgibaemych elementov pri ograničennych plastičeskich deformacijach. Soveršenstvovanije svarnych metalličeskich konstrukcij / Pod red. M. M. Žerbina. Kiev: Naukova dumka, 1992. 271 p. (in Russian).

13. Gorev V. V., Uvarov B. J., Filippov V. V., et al. / Pod red. V. V. Goreva. Metalličeskije konstrukciji. Vol I. Elementy stalnych konstrukcij. Moskva: Vysšaja škola, 1997. 527 p. (in Russian).

14. Jaras A., Kačianauskas R. Bimetalių dvitèjų siju būvio analizé, ivertinant plastinių deformaciju itaka. Statyba, Vol VII, No 2. V.: Technika, 2001, p. 122-130.

15. Dolinskij F. V., Michailov M. N. Kratkij kurs soprotivlenija materialov. Moskva: Vysšaja škola, 1988. 431 p. (in Russian).

16. Sawko F. Effect of strain hardening on the elasto-plastic behaviour of beams and grillages. Proceedings of the Institute of Civil Engineers, London, 28 aug. 1964, p. 489504.

17. Čižas A. P. Approksimacija zakona pazvitija plastičeskich deformacij pri upročniajušemsia materiale. Litovskij mechaničeskij sbornik, No 1-2. Vilnius, 1974, p. 14-15 (in Russian).

18. SniP II-23-81*. Stalnije konstrukciji. Gosstroj SSSR. Moskva: CTIP Gosstroja SSSR, 1990. 96 p. (in Russian).

19. Hearn E. J. Mechanics of Material 2. 3th ed. Oxford: Butterworth Heinemann, 1997. 539 p.

20. Kačianauskas R. Computer Methods in Multilevel Modelling of Beams and Shells. Vilnius: Technika, 1995. $395 \mathrm{p}$.

21. ANSYS. Theory Reference. Release 5.7. 2001 SAS IP, Inc. $(\mathcal{O}$

22. ANSYS. Elements Reference. Release 5.7. 2001 SAS IP, Inc. (C) 